\title{
A Research about Public Participation in the Process of Master-Urban-Planning in China-An Introduction of Practice of Gathering Public Opinion via Questionnaire Survey
}

\author{
Yang Fan \\ Urban Planning Department, College of Architecture and Urban Planning, Tongji University, Shanghai, China \\ Email: fanyangsh@tongii.edu.cn
}

Received 30 November 2014; revised 19 December 2014; accepted 1 January 2015

Copyright (C) 2015 by author and Scientific Research Publishing Inc.

This work is licensed under the Creative Commons Attribution International License (CC BY).

http://creativecommons.org/licenses/by/4.0/

(c) (i) Open Access

\begin{abstract}
This paper summarizes the practice of public participation via questionnaire survey in the process of working out Master Plan in China. Based on the analysis, the key issue to be desperately solved is the strategic content about urban long-term development, especially highlighted in conducting public participation by ways of questionnaire survey. In this regard, designing the questionnaire's content and subsequent distribution must provide convenience for townspeople to comprehend and to express themselves, and meanwhile questionnaire retrieving and analysis/conclusion shall be oriented by optimized scheme of spatial distribution. The importance of public participation cannot be overemphasized under the transformation of urban development in China. It will influence the decision-making of local government; it will have the communication between planners/ designers and government officials further strengthened.
\end{abstract}

\section{Keywords}

Master Planning, Planning Practice, Questionnaire Survey, Public Participation

\section{Introduction}

Urban and Rural Planning Law of the People's Republic of China (hereinafter referred to as "Urban-Rural Planning Law"), being in force dated 1 January 2008, gives very targeted accounts for the nodes concerning "public- 
ity and public participation" in planning, as specified in Article 26 at Chapter "Formulation of urban-rural planning" and Article 46 at "Amendments to urban-rural planning", where a claim is asserted for public participation respectively. Besides these, some cogent requests for public participation regarding "handling result of supervision/inspection upon urban-rural planning" and "amendments" are also being prescribed in Article 54 at Chapter "Supervision/inspection" and Clause 5 of Article 60 at "Legal responsibility".

From the two aspects of diversity of involvement groups and sociality of planning activity, the characteristics of "urban-rural planning" process is embodied in a repetitive cycle of action chain, i.e. "study-compilation-approval-implementation", in this regard requirement for "public participation" is pertinently configured into certain elements of "urban-rural planning law".

Being a planner, it is surely a prospective field worthy of constant exploration: how to carry out public participation in the practice of urban-rural plan-making, especially carry out public participation in performing authorized-planning under the responsibility and authority entrusted by the law, and how to provide real reference for planning and decision-making through public participation. In this paper, we would like to use public participation in Master Urban-Rural Planning of Tongling City, a prefecture-level city, demonstratively as an instance, with which we could have analysis upon certain specific practice for further discussion.

\section{Outlining Public Participation in Master Urban Planning for City Exemplified}

The very beginning of compiling Tongling City Master Urban Planning (2010-2030) was just at a time when the "12th Five-Year Plan" was just initiated into implementation nationwide, "Transformation and Development" turned out to be a common strategic choice for cities in the country, which was required not only for maintaining moderate growth but for everyone to share the achievements in an economic social development over the last 30 years' reform and opening-up. Within limited time given, the planning program should be capable of collecting public opinions as much as possible that they can be duly reflected in the planning scheme and have effective impact upon decision-making in urban development. Throughout comparison and investigation, it is finally decided that questionnaire survey shall be used for conducting public participation in the phase of Master Urban Planning program (Yang, 2012: p. 213-261).

\subsection{Goal Determination}

It is aimed at introducing public participation at phase of Master Urban Planning, having more consideration about the townspeople's opinion, and inclining audience to people's voice at time when an general strategy for development in the next twenty or thirty years is determined, in an attempt to exert influence upon decisionmaking by the municipal government to certain degree. The Planning Team proposed an inquiry of public opinions by distribution of questionnaires in quest for the model of public participation at phase Master Planning, and in the meanwhile, the Team would be trying to work out correlations between purpose of urban development strategy and value orientation of people via issuance, retrieving of questionnaire, and statistical analysis so that the key-points where they coincide and mutually support can be located. So the questionnaire would be titled as "Tongling City 2030-The Livable Habitat in my Mind".

At planning the whole activity of questionnaire survey, the Planning Team, apart from the questionnaire itself, is also deliberately thinking about the way of how to distribute questionnaire and how to retrieve and collect them so that some common townspeople, who are without background of certain working unit and regular channel of influence, may take part into it. Such arrangement is done in consideration of varied people groups with different cultural, economic and social background that the final statistical result of investigation on public opinions could be more fairly comprehensively reflecting the general public's will.

\subsection{Designing the Questionnaire}

\subsubsection{Study and Determine the Index System}

The theme of questionnaire is determined as "livability", which requires identification of "questionnaire suitability" to the existent index of livable cities, i.e. to determine the degree that these indices can be accepted and understood by common citizens in the city, such as whether it can be explicitly defined by interlocution and whether differentiability in such interlocution can be read (Zhang, 2007: p. 30-34). Those indices, which can only be determined by data analysis, scientific experiment and academic study, are in general cases not suitable 
to appear in the questionnaire for opinion polls.

Through screening, the Planning Team selected 42 questions at 6 major categories for questionnaire (Ministry of Housing \& Urban-Rural Development, 2007: p. 101) (as illustrated by Figure 1). First of all, "rating method" is prioritized in designing the answers for the questionnaire as to avoid appearance of quantitative data, which would be helpful for people to fast grasp the purpose of questionnaire and to more accurately express their own. Secondly, a "structured questionnaire" only provides limited answers, for which people is left to fall within the given answers, and such an arrangement would facilitate people of different social status extensively share one set of questionnaire and be lot easier for posterior statistical treatment with quantitative data such that studying correlations between variables can more easily be controlled and determined. Thirdly, at the end of questionnaire is furnished with "self-determined" column for meeting townspeople's requirement to express themselves. Looking at the questionnaires retrieved, there are a quite large number of people in Tongling City, who are highly caring about urban construction and development, and expressing their personal opinions.

\subsubsection{Design, Classification and Amendment of Questionnaire}

Firstly, at the time when the evaluation indices system of livable cities is transformed into questions and options that people involved may well understand, questions are raised at several aspects: the residents' overall impression to the city (image in their mind and willingness to migratory preference), the residents' hope for future (abstract and concrete), residents' comparison of the city with peripheral areas (cities within the province and domestic cities), etc. To facilitate later statistical analysis and cross analysis, the professionals also designed some questions to help collect vital information on townspeople in the questionnaire, including professional background, family structure, cultural background, financial income and value preference, etc.

Secondly, the Planning Team, in the light of difference of questionnaire's distribution channel and answering habit of group being investigated, separated the questionnaire into two categories as of individual questionnaire and family questionnaire, conducting a questionnaire survey in a city where network for opinion polls is incomplete, in which way "confidence ratio" (Shi, Wang, \& Lu, 2004: p. 109-112) ${ }^{2}$ is expected to be raised to certain degree. The Team collected personal information and willingness when an individual questionnaire is being collected meanwhile information on family, family member and family willingness being conveyed at "family meeting" are also collected when family questionnaire is issued.

Thirdly, a pre-investigation is performed by questionnaire designed by Planning Team while certain amendments are being made to the questionnaire in accordance with information feedback. At pre-investigation, some staffs working within planning administration system are chosen as survey respondents, who proactively rendered amendment proposals upon the way of question setting-up, inquiry and perspective for inquiry as well, in the light of professional knowledge and the knowledge about this city and understandings of seculars. Result from the bottom-line survey also reflects that answering rate to some questions being set up in the questionnaire is far below expectation, which possibly due to ambiguous connotations of the question itself, or probably because of the more sensitive nature of the question being raised such that respondents refused to give answers. All these can be amended by paying a return visit. The result of pre-investigation may objectively spur the Planning Team to avoid arbitrary assumptions, and demonstrates an important significance to help questionnaire achieve "localization and citizenization".

Fourthly, questionnaire survey should also render a balanced view of "political effect" in due course concerning questionnaire distribution and retrieving, when achieving technical purpose of compiling as planned. If overexcluded of propaganda and guidance effect, it would more likely result in consignor's sense of alienation such that implementation of questionnaire survey would be in lack of support, and validity of survey result's influence upon planning strategy would be greatly reduced.

\footnotetext{
${ }^{1}$ A rating method, is a way when answers are listed with differed ratings right below the questions given and then, the respondents shall tick one routine answer to proceed as per his/her own feelings. In this said survey, a 5-point scale table is being adopted, that is to say, citizens as respondents are to be given 5 options as of "very satisfied, satisfied, in general, not very satisfied and not satisfied" against degree that he/she is satisfied with.

${ }^{2}$ Confidence ratio is named as confidence degree, meaning that at evaluation upon population parameter by sampling, due to the random nature of samples, the conclusion is always uncertain. Therefore, using a statement of probability, i.e. an interval estimation method at mathematical statistics, which implying that if an estimated value and population parameter are controlled within certain range of allowable error, whatever such probability would be accordingly, then, such probability is to be treated as confidence degree. As indicated by confidence ratio for probability, no probability is implied within the incident itself and the reason why the incident is assigned with probability is because of the confidence proof within mind of the person who assigned such a probability.
} 


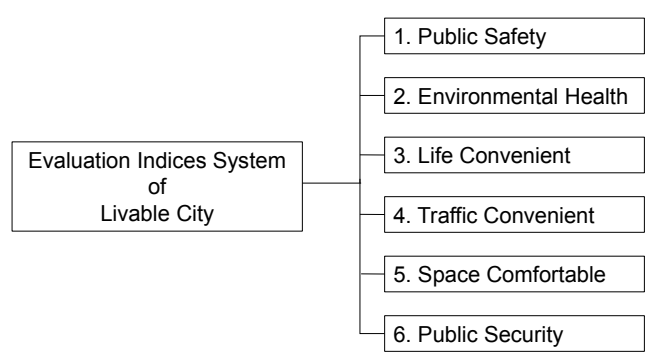

Figure 1. Framework designed for questionnaire on livable cities.

\subsection{Survey Accuracy}

According to general practice in the network for public opinion survey, survey accuracy (maximum allowable sampling error) is not only affected by sampling size but also correlated to variation of survey respondents, assumed confidence coefficient and method of sampling as well. Under circumstance when sampling method is relatively fixed, it necessitates total volume at sampling survey to be around $2.9 \%-3.5 \%$ of the whole population in the city, in which urban sample and rural sample shall be separately considered. In doing so, survey accuracy that total sampling volume may actually achieve, can be controlled and survey result would be more representative of the townspeople. The existent urban population in Tongling City is about 590,000 and as a result, overall sampling rate is defined as $3 \%$ on condition that no deviation would occur and $90 \%$ of confidence coefficient is guaranteed in the survey. As assumed that total 15,000 questionnaires are to be issued on the basis of total urban population, whereas considering the proportion of invalid questionnaire, it is then proposed to issue total 17,000 questionnaires but it requires that a structural equilibrium of respondents receiving questionnaires must be ensured.

\subsection{Designing the Process of Distribution and Retrieving of Questionnaire}

In comparison to designing questionnaire itself, a considerate distribution of questionnaire is as equally important as a retrieving. The Planning Team must in advance, putting their own on the scene, think about every likely scenario in distribution and any possible attitude and response of the townspeople to questionnaire under varied situations. Setting of these details would, to a rather considerable extent, affect the quality of respondents' answering and degree that statistical result would reflect people's true willingness.

\subsubsection{Pre-Propaganda to Townspeople}

As proposed by the Planning Team, a propaganda aiming at compiling Master Planning work and people's participation in the planning shall be conducted through Medias such as broadcasting, television, newspaper, government websites and bulletin board, etc. In view of the fact that number of publication and newspaper circulation account for total volume of questionnaires via channel of newspaper, it is then recommended that Evening Post or Morning Paper would be preferred or local commercial press with larger circulations shall be queued at option, and in the meantime, due to differed usage of internet amongst townspeople, it is therefore suggested that verification of IP address and establishing deadline shall be done when distributing questionnaire via internet.

\subsubsection{Issuance of Questionnaire}

The way of questionnaire issuance by stratified random sampling is being used in this survey whence it is separated into 2 major categories: individual questionnaire and family questionnaire, in which the family questionnaire appropriately helps to achieve an objective "unbiased questionnaire and confidence ratio" as designed and for this purpose, certain factors as of gender, age and vocation are taken into account in practice, aiming at an abstract concept of residents in the city. In a balanced view on residents with diversified background, these two major categories of questionnaires are issued via different channels.

Three channels as of "Media, governmental hierarchy and random operation" are used in this opinion poll, and except that random distribution is only targeted at individual questionnaire, another two channels are simultaneously targeted at questionnaire issuance for individual and family. For avoiding excessive influence of channel difference upon statistical result, the Planning Team established a restricted number of questionnaires 
for every channel of issuance as assigned. For "Media channel" it would include two categories as of "questionnaire for internet and newspaper". For "channel of governmental hierarchy", it would cover two categories as of "representatives to fill in" and "householders to fill in". As for "channel of random distribution", it is to be issued via distribution spots with concentrated stream of people, at railway station, civil plaza, park and commercial zone, respectively (Fan \& Lan, 2008: p. 96-118). This is a bold attempt in questionnaire survey, in terms of structuring such a channel system and coordinating the quantity of questionnaire across channels in China.

\subsubsection{Guidance for Issuance}

Issuance and retrieving of citizen questionnaire shall be conducted by local municipal planning administration. The Planning Team, from both technical and operation level, formulated an "Guidance for Questionnaire Issuance" designing to help the specific staffs better understand the significance of questionnaire classification and issuance via the given channels, and requested for a planned issuance as much as possible. For instance, the Planning Team total categorized 5 major questionnaires, including "questionnaire issued via internet (code A1), questionnaire issued via newspaper (code A2), representatives of the Local People's Congress/the Municipal CPPCC (code B1), decomposed questionnaire (code B2), and random questionnaire (code C1)", pertinent to the attributes of respondents and furthermore, quantity of issuance for each category is also restricted for avoiding biased information, and meanwhile any details to be noted against every category at the time of issuance are also forewarned.

Even if so, the local conductors of issuance are still exacted with impending problems such as a huge amount of questionnaires to be dealt with, explanations to be explicated and a variety of persuasions to be tried. Out of such concern, the local organizations responsible for issuance and retrieving appropriately exert certain measures with much flexible discretion, for instance: 1) In respect of the questionnaires to be issued complimentarily with newspaper, some elements in graphic design are being added while texture and printing quality are improved so as to elevate the townspeople's attention; 2) In regard of decomposed channel of issuance, educational resources as of primary school and middle school are being employed, in which the school authority is requested to distribute questionnaires as homework to every student, asking the students to complete questionnaire in immediate collaboration with parents.

For the secondary way, the Planning Team, for the time being, is not yet able to work out its impact upon confidence coefficient but separately have a another category in statistics. From viewpoint of improving the rate of retrieving and completing citizen questionnaire survey in a timely manner, this still appears to be a more flexible means for sound solution.

\subsection{Brief Analysis upon Questionnaire Retrieving and Statistics}

Finally, this survey totally retrieved questionnaires 15,212, in which including 49 copies as invalid (no single answer given) covering $0.3 \%, 720$ copies via random sampling (C1) retrieved from street covering $4.7 \%, 1102$ copies via newspaper questionnaire (A2) covering 7.2\%, 126 copies via representatives of the NPC/CPPCC (B1) covering $0.8 \%, 3148$ copies of family questionnaire (distributed by residential community, B2) covering $20.7 \%$ and 10,067 copies of family questionnaire (distributed in the school, B2) covering $66.2 \%$.

\subsubsection{Main Conclusion of Analysis}

After these over 15,000 copies of questionnaire going through standardized processing and being input into computer, the Planning Team primarily carried out classified and categorized statistical analysis and preliminary cross analysis, which arriving at brief conclusion as followed:

- Comprehensive evaluation by citizens to "livability" of habitancy is "In general" (covering 53.25\%), rate

${ }^{3}$ The established retrieving cycle for questionnaires via media channel is 15 days. Via regime channel, questionnaires to be filled by the Representatives is specially designed for every level of the deputy to the people's congress and member of the CPPCC (Chinese People's Political Consultative Conference), with 1 copy for each person and to be collectively submitted to the designated authorities; the decomposed questionnaire, which to be decomposed by governmental organs to level of district and residential community, then, according to different size of current population of Tongling City and in reference to geographical configuration of cultural composition for residents, the questionnaire is to be distributed upon issuance plan being defined. So, total 3500 copies of questionnaires are being issued, requiring one family to fill one copy. The established cycle of retrieving is 15 days, in which for 11 residential communities within city, each community is assigned with 200 copies, in total 220 copies. Peripheral countryside and towns are assigned with 1300 copies. For random issuance, the questionnaire shall be going out together with dedicated Postage-Prepaid envelopes, and posted to the designed mail boxes. In this way, total 500 copies are being issued. The established cycle of retrieving is 15 days. The principal for questionnaire issuance and retrieving is Planning Administration and in principle, a person with identity as civil servant would not be filling any questionnaires. 
"not satisfied" even going higher to $18 \%$. Therefore, this city has apparently low satisfaction with livability.

- Judgment upon whether the city is "livable" is not so much affected by educational background, as such the group with higher education, who always bestowed with better essential conditions in terms of income, working environment, residential environment and way of out-trip, are more likely to feel far better with "public safety" and "life convenient" than those with lower education.

- Professional background would impact upon people's awareness to hazard, visible or invisible. Office staffs, due to being influenced by fundamental information and life range, tend to be more caring about "air quality" whereas common citizens appear to be more concentrated upon visible cleanness of ambience. For instance, "refuse disposal" (Figure 2).

- Evaluation to "livability" is considerably affected by places people reside, which indicating that this city has not yet achieved "balanced" configuration amongst different sub-areas, arrangement of public facilities between municipal level and prefecture level is not in equilibrium and that usage of key public resources is not desirable, for instance: exploitation to coastal area along YZ River.

- In this survey, "representatives of the Local People's Congress/the Municipal CPPCC" are treated as relatively independent group, as indicated by result that the representatives' general satisfaction to "livability" of the city is comparatively higher than common citizens. Whereas, the single index of "not satisfied" with "environmental health" is higher than common citizens, illustrating that these representatives are in possession of much more knowledge and information in this aspect (Figure 3).

\subsubsection{Conclusion to Questionnaire Survey Affecting Planning Scheme}

- Impact upon strategic orientation to urban development.

It can be seen from analytical conclusion that the citizens are generally underrating "livability" of Tongling City, primarily focusing upon the two aspects of "environmental health" and "space comfortableness". Among these aspects, exacerbation of "environmental health" is closely related to development of the secondary industry in the city and varied categories within the secondary industry, for it is a common knowledge that copper metallurgy and further processing as backbone industries are being relied upon by Tongling City, which are naturally generating serious pollution to air, underground water and soil.

If observing the strategic goal of "transformation and development" established in this planning, urban industry are now under immediate pressure of "structural adjustment". Only when an industrial structure are transformed from energy-consumption and environmental destruction to sustainable growth and environmental friendliness can it be guaranteed that goal of building a "livable" city may come true and that quality of "growth" in the city can be ensured. For that concern, the result from this citizen questionnaire survey is directly providing a support that the Planning Team may recalibrate the positioning of the city's development under Urban Master Planning scheme, and thus became one of the crucial fundamentals in convincing the decision maker of local government.

- It affected structural adjustment for urban space structure overall arrangement.

Another index "space comfortableness" that is underrated is directly correlated to irrational urban space structure, with implication that developing the secondary industry, which to produce a great amount of pollutants of gas, effluent and waste residues, nearly occupied all the coastal lines along river such that the citizens can hardly feel being residing in an environment "beautifully landscaped with water and hills".

An urban transformation of development, is not only implying an industrial transformation but also suggests that urban construction concept is now gradually diverting from the former "focus upon production" to "more concentration on life" and that urban spatial structure is now under imminent pressure of "structural adjustment". It is obviously mandatory to allot much more of resources with local humanistic and featured environment to the residents in city, and to truly construct the city into a citizen's "amiable homeland" so that people can "share the fruit" of economic growth and social accumulation since the country's reform and opening-up.

- It affected structural recalibration for planning the urban land-use as a whole.

"Structural adjustment" of urban industrial and spatial arrangement would inevitably be an impact upon urban land-use when more industries, which with less occupation of land resources and higher economic output and higher contribution to employment, would emerge, and more space and facilities relevant to life, leisure and tourism shall be guaranteed and built, for which concern the ratio for varied land-use under Master Planning is thus being optimized and adjusted.

- It affected the way of communication between Planning Team and administrators of local government. 


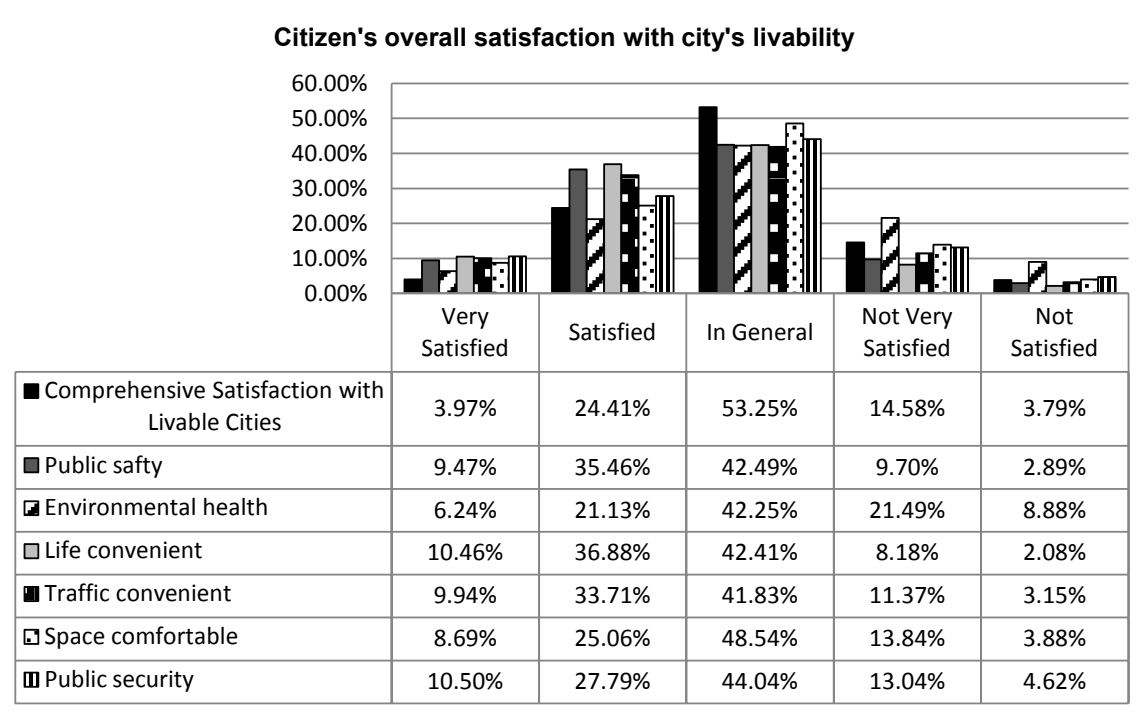

Figure 2. Analysis on people's overall satisfaction with city "livability".

\begin{tabular}{|c|c|c|c|c|c|}
\hline \multicolumn{6}{|c|}{ Representatives' Overall Satisfaction with "Livability" } \\
\hline \multicolumn{6}{|l|}{$\begin{array}{l}70.00 \% \\
60.00 \%\end{array}$} \\
\hline \multicolumn{6}{|l|}{$50.00 \%$} \\
\hline $40.00 \%$ & & & & & \\
\hline $30.00 \%$ & & & & 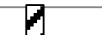 & \\
\hline $10.00 \%$ & & & & & \\
\hline 0.0070 & $\begin{array}{c}\text { Very } \\
\text { Satisfied }\end{array}$ & Satisfied & In General & $\begin{array}{l}\text { Not Very } \\
\text { Satisfied }\end{array}$ & $\begin{array}{c}\text { Not } \\
\text { Satisfied }\end{array}$ \\
\hline $\begin{array}{c}\text { - Comprehensive Satisfaction with } \\
\text { Livable Cities }\end{array}$ & $0.00 \%$ & $40.38 \%$ & $46.15 \%$ & $9.62 \%$ & $3.85 \%$ \\
\hline$\square$ Public safty & $17.74 \%$ & $62.10 \%$ & $16.94 \%$ & $3.23 \%$ & $0.00 \%$ \\
\hline$\square$ Environmental health & $4.03 \%$ & $19.35 \%$ & $40.32 \%$ & $30.65 \%$ & $5.65 \%$ \\
\hline$\square$ Life convenient & $14.40 \%$ & $56.80 \%$ & $28.00 \%$ & $0.80 \%$ & $0.00 \%$ \\
\hline Traffic convenient & $9.60 \%$ & $52.00 \%$ & $30.40 \%$ & $5.60 \%$ & $2.40 \%$ \\
\hline Space comfortable & $5.60 \%$ & $32.80 \%$ & $50.40 \%$ & $9.60 \%$ & $1.60 \%$ \\
\hline m Public security & $12.90 \%$ & $45.16 \%$ & $37.90 \%$ & $4.03 \%$ & $0.00 \%$ \\
\hline
\end{tabular}

Figure 3. Analysis on representatives' overall satisfaction with "Livability" in the same city.

Now in China, as a matter of fact, the planner and urban administrator are all, somehow, ignoring the interests of urban residents - the planner himself is too much indulging in self-perfection while the administrator is that much keen on his political achievements.

On the one hand, the planner acquired support of "social rationality" to "technical rationality" from the citizens; and on the other hand, the urban administrators are subject to no less pressure of "popular project" than that of "political project" when they are more inclined to accept reasonable suggestions by the planner at decision-making. Whereas, the relation between planner and urban administrator, is now gradually evolving from that old fashion, i.e. party "giving persuasion" versus party "rendering service", to a new collaborative relationship that both parties may think for the sake of the general public and for the prospective days of city to come. This kind of collaborative relationship is truly built upon the solid foundation of serving the citizens' common interests, and its sense of achievement shall neither be built upon "political performances" nor upon "Self-fulfilling".

\section{Discussions}

We are procured by this work to have more thinking about certain questions. 


\subsection{Form and Phased Options for Public Participation in Urban Planning}

Current problems with public participation in urban planning practice are concluded by many scholars as procedural dilemma and substantial predicaments, and its root cause is resting with a fact that being residents in a city and user of urban constructional products, the citizens are all along in lack of rights of speech in terms of what to be decided and how to be constructed, not to mention the power in decision-making. Theoretically speaking, urban administrator and urban planner, being endowed with professional/technical abilities and with power to allocate resources, are exercising the rights "in place of" the citizens in this respect whereas, if looking at reality, it would be found that both of them are incompetent at playing the given roles.

By introducing public participation at phase of compiling the Urban Master Plan, the citizen's opinions are in the end adopted in the form of planning statutory fruits, and we should say that this is not an exclusive phase and an only way for public's participation in urban planning. Questionnaire survey, perhaps, is one way for public participation, which is implemented with visible influence, capable to be operated by someone and can likely be realized but it is also to be noted that such "achievable influence" is only incarcerated within planning text and drawing completion while any effectual conduct with impact upon urban construction is not beheld.

\subsection{Key Issues for the Public Participation with Questionnaire Survey as Media}

Several key nodes in questionnaire survey would be an influence upon the result of public participation:

- Subject selection. The subject selected for questionnaire survey must be explicit and definite, and can be generally accepted whereas, if in lack of directivity accordingly, it would turn out to be hard for common citizens to understand, and answers rendered be difficult to reflect reality while with its result hardly to have efficient impact upon planning. And in the meanwhile, subject selection must not only be pertinent to perception for the townspeople on daily basis but also be corresponding to the major topics in public opinion, so as to avoid any excessively professional statement, for instance, urban positioning, direction for urban development. These terminologies are not easy for common citizens to precisely comprehend.

- Trying the utmost to procure universality of public participation. Being different from research questionnaire survey, public participation in the process of urban planning practice, especially at decision-makings concerned with vitally important issues in the city, must be ensured of the questionnaire's universality. Universality of public participation is not only bound by general volume of questionnaire but also confined by spatial scale and range of social class. Out of such concerns, a good overall planning is then at immediate demand. For questionnaire survey with an extensive participation of citizens, in spite of its time-consuming, labor-intensive and fund-costing nature, persuasiveness of statistical result would be more intensely strengthened and propaganda effect in the course of questionnaire being carried out is to be greatly enhanced, and the mechanism, which leading the common citizens to transit from "right to learn the truth" to "right to participate", shall be functionally highlighted, and proved to be an effectual public participation in the urban planning where public opinions are duly respected.

- Phased design for participation. A desirable public participation in urban planning is a phased, stratified and dynamically evolved course. The Planning Team once assumed that some citizen colloquia can be introduced in due course of compiling and in reference to experts' argumentation or report by certain departments, after which another questionnaire survey can be then conducted for further learning about any changes with citizen's opinions. Nevertheless, this assumption, due to a series of factors, such as that there is likely huge amount of work at later stage when the focus of compiling work would be gradually shifting to approval procedures and demonstration effect of questionnaire survey is to be exerting more greatly than its guidance in reality, it is in the end had to be renounced. Apparently, once having proceeded a large scaled public participation, the planners' understanding to public participation would be somewhat different from the level of theory, in which public participation is to achieve certain ideal objective, despite of what kind of form for participation, its objective is all for peoples' willingness to be effectively expressed and for public opinions to be appropriately "released".

- Design and distribution of questionnaire. The question setting for the questionnaire survey must be up to the understanding by citizens or otherwise, a common citizen may, by the simplest way, acquire his/her own perception at answering these questions. Here, "citizen" is an abstract concept with an implication of differed age structure, varied background of education and knowledge level, diverse condition of work and financial income and of course, dissimilar origin and cultural background, etc. Learning, perceiving and stud- 
ying to a city is the fundamental for accomplishment of abovementioned designs and moreover, conducting

in-depth survey of current situation, working closely with local planning departments and carrying out pre-investigation for questionnaire would be a better solution for tackling this problem.

In the course of distributing and retrieving the questionnaires, it is mandatory not only to have the planner exert guidance but also to refrain it from excessively affecting statistical result. It would be the most ideal state for public to participate in the questionnaire survey that the citizen may feel the delightfulness and experience the effectiveness of participation (Table 1).

\subsection{The Objective Is to Achieve a Multilateral Cooperation}

A success of questionnaire survey is lying in the facts that understanding the significance of this survey between planning clients and survey working team is retained as consistent, and that every party has accomplished his objectives through collaboration, respectively, in which the local government is articulating its strategic objectives and development guidelines via questionnaire survey, and the Planning Team has the positioning and technical route explicitly defined via questionnaire survey, and the citizens have acquired further understanding to the planning while conveying their own opinions.

When inclining audience to public opinion and paying respect to public willingness, the planner did not spare any opportunities for active exertion of specialist's value guidance - not only the urban administrator is convinced to have more rational decision-makings but the citizens are educated to even more precisely understand correlation between "planning language" and reality of urban life.

In effect, a single questionnaire can neither possibly cover all the urban problems nor for such complicated urban planning bring about all-inclusive information on public opinion while citizens are not necessarily maintaining that certain problems are so closely bound up with their life. Factors, as of distinctively different background of intelligence, asymmetrical information and obstruction from design regime, are all along having influence upon public participation in urban planning. Nevertheless, public participation into a process has thus created a kind of collaboration correlate to personal interests, and in this scenario the interests of an individual citizen may associate his/her own opinions with certain issues, whereas these opinions may not be directly correlated to the individual life but would be taking effect by public participation into practical activities such that finally citizens acquired hands-on understanding to the common interests (Yang, 2012: p. 260).

\section{Conclusion}

No matter at what phase and in what form for public participation, it all necessitates patience of the planner, except for dedicating his professional passion to the course. The key factors are still lying in whether the planners are willing to condescend getting close to citizens' life, instead of indulging in heroic feeling about cynical talks, despite that current regime, mechanism, funding and channel, etc. are all to become the excuses or pretext for ill-developed public participation.

Table 1. Understanding the key points for public participation in the form of questionnaire survey.

\begin{tabular}{|c|c|c|c|}
\hline Questions Three vital parts & Participation mechanism & Content of participation & Effect of participation \\
\hline 1) Possible actions to be taken & $\begin{array}{l}\text { Questionnaire design } \\
\text { Channel for issuance }\end{array}$ & $\begin{array}{c}\text { Subject selection } \\
\text { Designing questionnaire }\end{array}$ & $\begin{array}{c}\text { Embodiment of scheme } \\
\text { Posted suggestions } \\
\text { How to adopt suggestions as } \\
\text { posted }\end{array}$ \\
\hline Key points for solution & $\begin{array}{l}\text { (Governmental guidance) } \\
\text { Objectivity }\end{array}$ & $\begin{array}{l}\text { (Subject selection) } \\
\text { Comprehensibility }\end{array}$ & $\begin{array}{l}\text { (Adopting) } \\
\text { Observability }\end{array}$ \\
\hline $\begin{array}{l}\text { 2) Significance and function for } \\
\text { planning process }\end{array}$ & Institutionalization & Studying the planning process & $\begin{array}{l}\text { Popularization of planning } \\
\text { knowledge }\end{array}$ \\
\hline Key points for solution & $\begin{array}{l}\text { Mechanism from bottom } \\
\text { to top }\end{array}$ & $\begin{array}{l}\text { Visible and readable Construing } \\
\text { of professional content }\end{array}$ & Vulgarized planning knowledge \\
\hline $\begin{array}{l}\text { 3) Interrelationship between three } \\
\text { vital parts }\end{array}$ & $\begin{array}{l}\text { Content subject to } \\
\text { mechanism }\end{array}$ & Effect subject to content & Effect impact upon mechanism \\
\hline
\end{tabular}


In immediate view of this planning experience, the public participation in the form of questionnaire survey apparently necessitates a construction of localized "system of public-opinion-survey network", whether it is to accomplish the goal of "procedural" or "substantial" participation.

Popularization of planning knowledge and transit of the planning "language" from professional know-how to common-sense information become the most crucial conditions for enhancing the citizens' recognition to urban planning and also the fundamentals for procuring the citizens to take part in action.

\section{References}

Fan, B. N., \& Lan, Z. Y. (2008). Public Management Research and Quantitative Analysis Method. Beijing: Science Press.

Ministry of Housing \& Urban-Rural Development (2007). Study on Perfection of Planning Indices System. Beijing: Architecture \& Building Press.

Shi, F., Wang, F., \& Lu, J. (2004). Exploration and Research for Determining Sampling Rate on Investigating Urban Residents Trip in China. Journal of Highway and Transportation Research and Development, 21, 109-112.

Yang, F. (2012). Special Edition: Investigation Report on Public Participation. Attachment of "Tongling City Master Urban Planning (2010-2030)". Shanghai: Studio of Tongling Urban Master Planning, Shanghai Tongji Urban Planning \& Design Institute.

Zhang, W. Z. (2007). Study on Intrinsic Meaning of the Livable City and the Evaluation System of Livable City. Urban Planning Forum, 167, 30-34. 
Scientific Research Publishing (SCIRP) is one of the largest Open Access journal publishers. It is currently publishing more than 200 open access, online, peer-reviewed journals covering a wide range of academic disciplines. SCIRP serves the worldwide academic communities and contributes to the progress and application of science with its publication.

Other selected journals from SCIRP are listed as below. Submit your manuscript to us via either submit@scirp.org or Online Submission Portal.
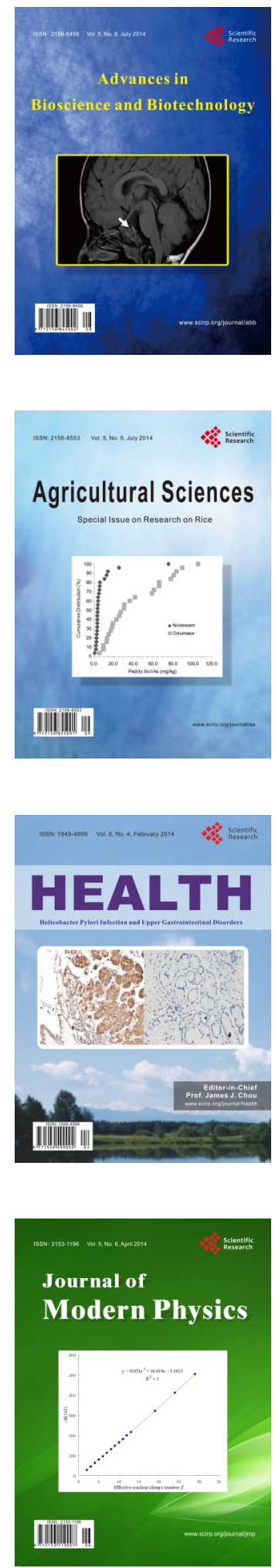
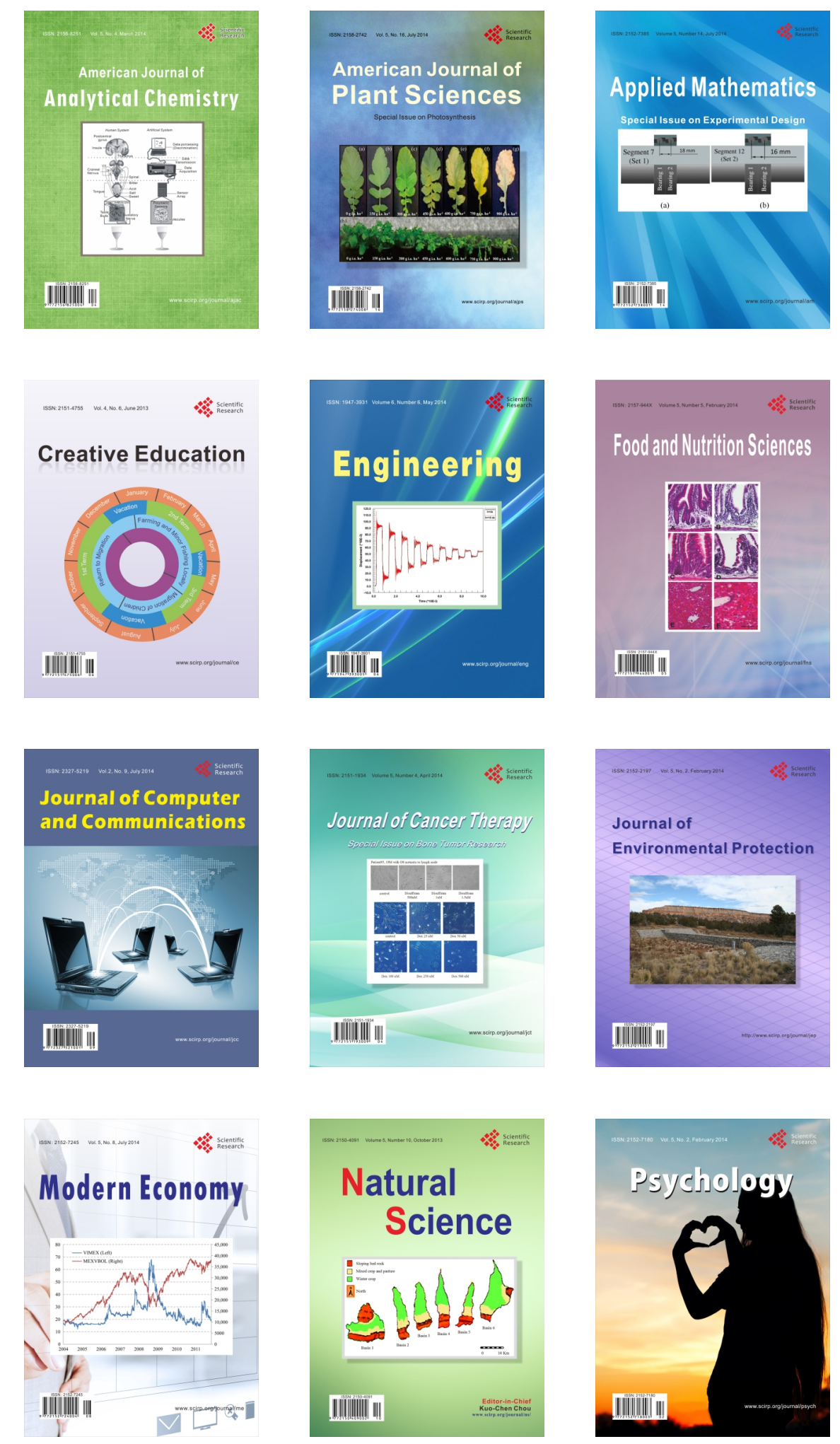